Gut, 1988, 29, 778-781

\title{
Frequency of pancreatitis in fulminant hepatic failure using isoenzyme markers
}

\author{
R J EDE, K P MOORE, W J MARSHALL, AND ROGER WILLIAMS \\ From the Liver Unit and Department of Chemical Pathology, Kings College Hospital, Denmark Hill, London
}

SUMMARY Evidence of acute pancreatitis was sought in 35 patients with fulminant hepatic failure. Total amylase was raised in 22 patients and isoenzyme separation showed a distinct P3 isoenzyme (indicative of pancreatitis) in 14. In four patients with marked hyperamylasaemia $(>1000 \mathrm{U} / \mathrm{l})$ the predominant isoenzyme was the salivary fraction. Pancreatic lipase was abnormally raised $(>200$ $\mathrm{U} / \mathrm{l}$ ) in 34 patients but exceeded $1000 \mathrm{U} / \mathrm{l}$ in 12 of the 14 with a distinct P3 isoenzyme. Thus on the basis of a distinct $P 3$ isoenzyme of amylase and an increased pancreatic lipase activity evidence of pancreatitis was found in $34 \%$ of patients in this series.

Acute pancreatitis has been a recognised complication of acute viral hepatitis for more than 40 years 1 and more recently has been reported to occur in patients with fulminant hepatic failure. ${ }^{2-4}$ These reports have been based largely on retrospective analyses of post mortem findings. In a combined prospective and retrospective study, Parbhoo et $\mathrm{al}^{5}$ found that total serum amylase was increased in $33 \%$ of patients with fulminant hepatic failure (FHF) as defined by Trey and Davidson. ${ }^{6}$ Interpretation of raised serum amylase can be difficult in this group of patients, however, because a number of the complications, including renal failure ${ }^{7}$ and pneumonia, are known causes of hyperamylasaemia ${ }^{89}$ Furthermore, clinical diagnosis is made difficult as a result of encephalopathy which may mask any symptoms or signs of pancreatitis. In other clinical situations pancreatitis carries a significant mortality and may be amenable to a variety of therapeutic manoeuvres. ${ }^{1011}$ We therefore sought evidence of this complication in patients with FHF by means of more specific tests for acute pancreatitis, namely the presence of the P3 isoenzyme of amylase and the pancreatic isoenzyme of lipase.

\author{
Methods \\ PATIENTS \\ Thirty five patients (14 men, 21 women) aged \\ Address for correspondence: Dr Roger Williams, FRCP, Liver Unit, King's \\ College Hospital, Denmark Hill, London SG5 9RS. \\ Received for publication 16 December 1987.
}

between 14 and 64 (mean age 32 years) admitted with FHF in grade 3 or 4 coma were studied. The causes of hepatic failure were paracetamol overdose (27 cases), non-A non-B hepatitis (four cases), hepatitis B (three cases) and hepatitis A (one case). A control group of 22 healthy laboratory personnel - 12 men (mean age 29 years) and 10 women (mean age 28 years) was also studied.

Blood samples were taken within 24 hours of admission and sera stored at $-20^{\circ} \mathrm{C}$ for subsequent analysis. Total amylase activity was determined by hydrolysis of a dyed starch matrix (Phadebas, Pharmacia Diagnostics). Pancreatic lipase was determined using a turbidimetric assay ${ }^{12}$ (Boehringer Mannheim). Amylase isoenzymes were separated essentially as described by Legaz and Kenny. ${ }^{13}$ Electrophoresis was carried out at $4^{\circ} \mathrm{C}$ in a Shandon tank on cellulose acetate membranes (Cellagram II) at a constant current of $0.5 \mathrm{~mA} / \mathrm{cm}$. A discontinuous buffer system was used, consisting of Trisma $0 \cdot 15$ $\mathrm{mmol} / \mathrm{l}$ titrated to $\mathrm{pH} 9 \cdot 15$ with boric acid in the anodal chamber and Barbital buffer $0.03 \mathrm{mmol} / \mathrm{l}, \mathrm{pH}$ 8.6 in the cathodal chamber. The cellulose acetate membranes were soaked before electrophoresis in a solution containing equal volumes of the cathodal and anodal buffers together with bovine serum albumin at a final concentration of $1 \%$. Serum was applied with a $0.4 \mu \mathrm{l}$ applicator (Shandon) suitable for multiple applications. Samples with a total amylase activity of greater than $1000 \mathrm{U} / \mathrm{l}$ had a single application while those with activities of $500-1000$ $\mathrm{U} / \mathrm{l}$ and less than $500 \mathrm{U} / \mathrm{l}$ had two and three applica- 
tions respectively. Identification of amylase isoenzymes becomes difficult in samples with a total amylase activity $<200 \mathrm{U} / \mathrm{l}$. A control consisting of pooled saliva and fluid from a pancreatic pseudocyst, diluted to yield an activity of approximately $1000 \mathrm{U} / 1$, was run on each cellulose acetate membrane. Isoenzymes were located by incubation of the membrane on agarose gels impregnated with Phadebas tablets. ${ }^{14} \mathrm{Up}$ to six isoenzymes may be separated by this means and are termed salivary (S1, S2, S3) and pancreatic (P1, P2, P3). Migration occurs towards the anode, with the salivary fraction migrating more rapidly. The relative contributions (as estimated as a percentage of total) were assessed independently by visual inspection in a single blind manner by two experienced observers (KPM and WJM). There was excellent agreement between the two observers and their assessments of the relative contributions of each isoenzyme, which were consistent when repeated after an interval of several days. A distinct P3 was said to be present when this fraction exceeded an estimated $5 \%$ of total amylase and a faint P3 isoenzyme present if just visible. In practice, a distinct P3 isoenzyme was only seen in patients with an amylase activity greater than $400 \mathrm{U} / \mathrm{l}$.

The severity of liver damage was assessed by prolongation of the prothrombin time; standard biochemical tests of liver and renal function were performed on a multichannel autoanalyser (Technicon SMAC, Technicon Instruments, Basingstoke, UK).

STATISTICAL ANALYSIS

Difference between groups of patients were analysed using the Wilcoxon's rank test and $\chi^{2}$ test as appropriate. All results are expressed as mean (SE).

\section{Results}

Total amylase activity was normal in all 22 controls (normal range 70-300 U/l) and separation of amylase isoenzymes showed the $\mathrm{P} 2, \mathrm{~S} 1 \mathrm{~S} 2$ pattern in 13 and a $\mathrm{P} 2$, S1 pattern in the remaining nine subjects. In none of the 22 subjects was a P3 isoenzyme detected. Pancreatic lipase was not assayed in this group as we have previously found close agreement in normal subjects with the manufacturers' quoted normal range $(50-200 \mathrm{U} / \mathrm{l})$ in healthy volunteers. Electrophoresis of the pooled control yielded five peaks with a P2P3, S1S2S3 pattern.

Total amylase activity was greater than $300 \mathrm{U} / \mathrm{l}$ in 22 of the 35 patients and in 11 values exceeded 1000 U/l. In 34 of the 35 patients pancreatic lipase activity exceeded $200 \mathrm{U} / \mathrm{l}$ and in 12 of these the lipase activity was greater than $1000 \mathrm{U} / \mathrm{l}$.

Amylase isoenzyme separation was carried out in

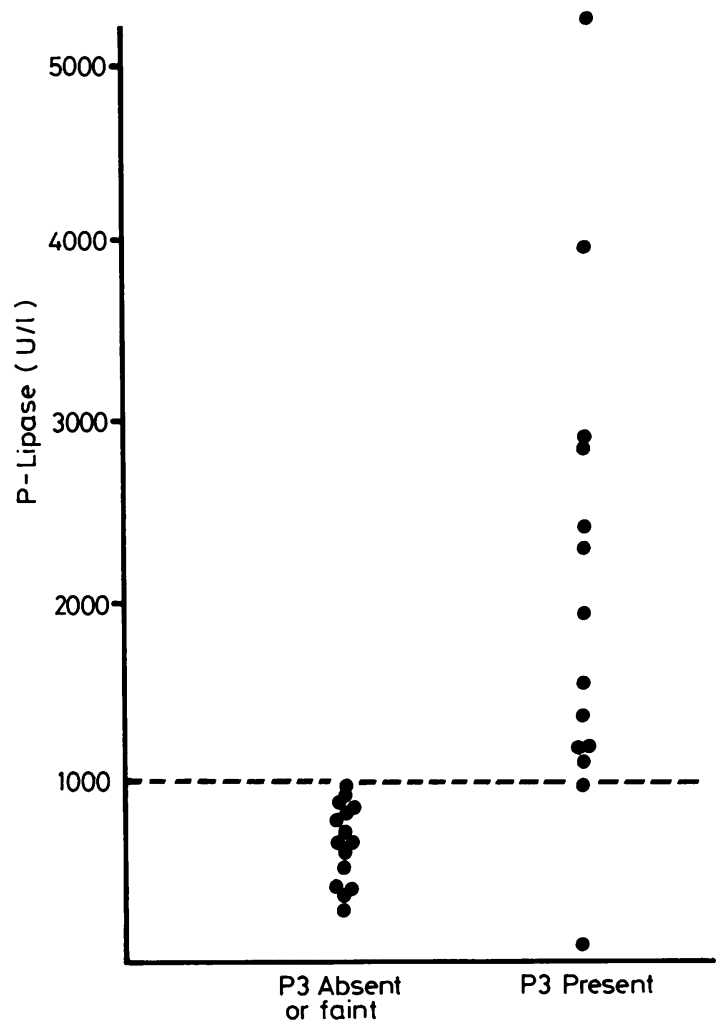

Figure Relationship between $P$-lipase activity and presence of the P3 isoenzyme in patients with fulminant hepatic failure.

the 29 patients with total amylase exceeding $200 \mathrm{U} / \mathrm{l}$. A distinct $P 3$ isoenzyme was shown in 14 patients and in 12 pancreatic lipase was greater than $1000 \mathrm{U} / \mathrm{l}$ (mean $2300 \mathrm{U} / \mathrm{l}$ (385) (SE)). The P3 isoenzyme was not detectable in seven of the patients and in eight was only faintly present - for statistical purposes these two groups will be considered together (Figure). The difference in the mean pancreatic lipase between those patients with a distinct P3 isoenzyme and those without was significant $(p<0.005)$, whereas the difference between the mean amylase values was not $(p>0.05$, Table 1$)$. Four of the seven patients with no detectable P3 isoenzyme had a total amylase greater than $1000 \mathrm{U} / \mathrm{l}$ and this increase was due predominantly to a rise in the salivary fraction.

The effect of renal impairment on total amylase and pancreatic lipase is shown in Table 2. There was no significant difference between the mean amylase or pancreatic lipase in those patients with significant renal impairment (creatinine $>150 \mu \mathrm{mol} / \mathrm{l}[>1.7$ $\mathrm{mg} / \mathrm{dl}]$ ) and those without. 
Table 1 Relationship of total amylase and P-lipase to the presence of the P3 isoenzyme

\begin{tabular}{llll}
\hline & No/Faint P3 & Distinct P3 & \\
\hline Patients (n) & $15 / 29$ & $14 / 29$ & \\
P-lipase (U/1) & $624(46)$ & $2308(385)$ & $\mathrm{p}<0 .(0) 5$ \\
Amylase (U/1) & $615(140)$ & $1064(176)$ & $\mathrm{NS}$ \\
\hline
\end{tabular}

Values are mean (SE).

Table 2 Total amylase and pancreatic lipase in relation to renal function

\begin{tabular}{lccc}
\hline & \multicolumn{3}{l}{ Serum creatinine } \\
\cline { 2 - 4 } & $<150 \mu$ mol/l & $>150 \mu m o l / l$ & \\
\hline Patients (n) & 18 & 17 & NS \\
Amylase U/l & $668(161)$ & $8(14(143)$ & NS \\
Pancreatic lipase U/l & $1187(279)$ & $1284(298)$ & \\
Creatinine $\mu \mathrm{mol} / \mathrm{I}$ & $94(8)$ & $466(62)$ & \\
\hline
\end{tabular}

Values are mean (SE).

The mean prolongation of the prothrombin time was greater in patients with a distinct $\mathrm{P} 3$ isoenzyme (80 (12) seconds) than in those without (55 (6.8) seconds), but this difference was not statistically significant. Similarly there was no significant difference in the serum aspartate-amino transferase or calcium in those patients with and without the P3 isoenzyme. There was a significant difference, however, between serum bicarbonate in those patients with a distinct $\mathrm{P} 3$ isoenzyme and those without (HCO3 $17(1.2) \mathrm{mmol} / \mathrm{l}$ and $23(1.2) \mathrm{mmol} / \mathrm{l}$ respectively) and this difference could not be accounted for by varying degrees of renal impairment. Indeed, of the 29 patients in whom amylase isoenzymes were separated, a distinct P3 isoenzyme was present in five of the 14 patients with renal impairment (creatinine $>150 \mu \mathrm{mol} / \mathrm{l}$ ) and nine of the 15 patients without.

The overall survival of this group of patients was $43 \%$ comprising 13 of the 27 patients with FHF caused by paracetamol overdose and two of the eight patients with viral hepatitis. There were eight deaths among the 14 patients with a $\mathrm{P} 3$ isoenzyme and eight deaths in the 15 patients without.

\section{Discussion}

A number of studies have now shown that the P3 isoenzyme of amylase is a more specific marker of acute pancreatitis than serum amylase alone. ${ }^{131510}$ Using this test in addition to an assay for pancreatic lipase we have found biochemical evidence of acute pancreatitis in $34 \%$ of patients with FHF, a frequency close to that found in necropsy studies. ${ }^{+5}$ Up to now the diagnosis has usually been based on the finding of a grossly raised amylase activity $(>1000 \mathrm{U} / \mathrm{l})$. The present results, however, suggest that a significant number of patients (six of 23) with an amylase of less than $1000 \mathrm{U} / \mathrm{l}$ have biochemical evidence of pancreatitis. Furthermore, one third of patients with a grossly raised total amylase had salivary hyperamylasaemia with no detectable P3 isoenzyme and P-lipase less than $1000 \mathrm{U} / \mathrm{l}$. Although termed 'salivary' this isoenzyme of amylase may be derived from many tissues other than salivary gland, such as lung and ovary ${ }^{17}$ and it may also be raised after intracranial haemorrhage.$^{18}$ Its origin in the patients with FHF is unclear although it may be related to respiratory disease.

While identification of the P3 isoenzyme greatly improves the diagnostic accuracy, this technique is time consuming. The pancreatic lipase assay, however, is rapid, cheap, and easy to do. We suggest that a higher cut off $(1000 \mathrm{U} / \mathrm{l})$ be used before making the diagnosis of pancreatitis in FHF, as only such values were associated with the presence of the P3 isoenzyme. It is of interest that the mortality in patients with evidence of biochemical pancreatitis was not significantly different from those patients without this complication. It would seem therefore, that in the majority of cases the pancreatitis was not severe, although a small increase in mortality could have been obscured by the overall high mortality of the group $(57 \%)$. It was noted that the serum bicarbonate was lower in those patients with evidence of pancreatitis and that this difference was not caused by renal failure. This may be because of a higher incidence of lactic acidosis in this group, which is a recognised complication of FHF,,$^{19}$ although serum lactate was not measured in this study. Although renal failure may result in hyperamylasaemia there is no direct correlation between total serum amylase and the severity of renal failure. In this study we found no significant difference in total serum amylase in those with and those without renal impairment.

With regard to the pathogenesis of pancreatitis in FHF the earliest reports considered this complication was the result of direct cytopathic effect of the virus concerned. ${ }^{23}$ While such effects may be important in cases of viral hepatitis, it is apparent that pancreatitis may also complicate FHF caused by paracetamol overdose and halothane hepatitis. While the precise mechanism involved remains uncertain, the demonstration of increased lysosomal activity in the sera of patients with FHF by Gove et $a l^{20}$ may well be of relevance. Circulating lysosomal proteases are known to damage other organs including the lungs ${ }^{21}$ and kidney ${ }^{22}$ and presumably could also damage the pancreas. Pancreatic damage could also be mediated by the formation of free radicals which are present in increased concentrations in FHF. In this context it is of interest that experimentally induced pancreatitis 
may be ameliorated by infusion of the free radical scavengers superoxide dismutase and catalase. ${ }^{23}$ Attempts to limit free radical formation and lysosomal enzyme release may reduce the incidence of pancreatitis and would be worth evaluating in patients with FHF.

\section{References}

1 Lisney AA. Infective hepatitis in Leicestershire; a survey of 1,062 cases. Proc $R$ Soc Med 1944; 37: 165.

2 Geokas MC, Olsen H, Swanson V, Rinderknect H. The association of viral hepatitis and acute pancreatitis. California Med 1972; 117: 1-7.

3 Wands JR, Salyer DC, Boitnott JK, Maddrey WC. Fulminant hepatitis complicated by pancreatitis. Hopkins Med J 1973; 133: 156-60.

4 Ham JM, Fitzpatrick P. Acute pancreatitis in patients with acute hepatic failure. Dig Dis 1973; 18: 1079-83.

5 Parbhoo SP, Welch J, Sherlock S. Acute pancreatitis in patients with fulminant hepatic failure. Gut 1973; 14: 428.

6 Trey C, Davidson C. The management of fulminant hepatic failure. Prog Liver Dis 1970; 3: 282-98.

7 Wilkinson SP, Meadie H, Arroyo V, Williams R. Frequency of renal impairment in paracetamol overdose compared with other causes of acute liver damage. J Clin Pathol 1977; 30: 141-3.

8 Berk J, Fridhandler L, Ness R. Amylase and isoamylase activities in renal insufficiency. Ann Intern Med 1979; 90: $351-3$.

9 Berk J, Shimamura J, Fridhandler L. Amylase changes in disorders of the lung. Gastroenterology 1978; 74: 1313-7.

10 Tykka $\mathrm{H}$, Mahlbeg $\mathrm{K}$, Pantzar P, Tallber T. Phospholipase $A_{2}$ inhibitors and their possible clinical use in the treatment of acute pancreatitis. Scand $J$ Gastroenterol 1980; 15: 525-8.
11 Standfield N, Kakkar VV. Prostaglandins and acute pancreatitis - experimental and clinical studies. $\mathrm{Br} J$ Surg 1983; 70: 573-6.

12 Ziegenhorn J, Neumann U, Knitsch KW, Zwez W, Roeder A, Lenz H. Lipase - test characteristics. Medica $1980 ; 1: 1-7$.

13 Legaz M, Kenny M. Electrophoretic amylase fractionation as an aid in diagnosis of pancreatic disease. Clin Chem 1976; 22: 57-62.

14 Benjamin DR, Kenny MA. Clinical value of amylase isoenzyme determinations. Am J Clin Pathol 1974; 62: 752.

15 Leclerk P, Forest JC. Variations in amylase isoenzymes and lipase during acute pancreatitis and other disorders causing hyperamylasaemia. Clin Chem 1983; 29: 1020-3

16 Collins REC, Frost SJ, Spittlehouse KE. The $P_{3}$ isoenzyme of serum amylase in the management of patients with acute pancreatitis. Br J Surg 1982; 69: 373-5.

17 Warshaw $\mathrm{A}$, Lee $\mathrm{KH}$. Characteristic alterations of serum isoenzymes of amylase in disease of liver. pancreas, salivary gland, lung and genitalia. J Surg Res 1977; 22: 362-9.

18 Bouwman DL, Altshuler J, Weaver D. Hyperamylasaemia: A result of intracranial bleeding. Surgery 1983; 94: 318-23.

19 Bihari D, Gimson AES, Williams R. Lactic acidosis in fulminant hepatic failure - some aspects of pathogenesis and prognosis. J Hepatol 1985; 1: 405-16.

20 Gove CD, Wardle EN, Williams R. Circulating lysosomal enzymes and acute hepatic necrosis. J Clin Pathol 1981; 34: 13-6.

21 Toomasian JM. Effects of hepatic autologous lysosomal enzymes in rat lung. Surg Forum 1976; 27: 173-4.

22 Lefer AM. The role of lysosomes in circulatory shock. Life Sci 1976; 19: 1803-9.

23 Sanfey H, Bulkey GB, Cameron JL. The role of oxygenderived free radicals in the pathogenesis of acute pancreatitis. Ann Surg 1984; 200: 405-13. 